\title{
Meus pais não ousaram falar
}

\section{(Educação Sexual) *}

\author{
FRANCISCO ALVIM **
}

Este texto, apesar de muito antigo, tem exactamente 25 anos, guarda a meu ver uma frescura que só a juventude permite.

Relendo o texto agora, chego à conclusão que já não era capaz de o escrever como fiz. Não porque esteja antiquado, a psicanálise é sempre actual, mas havia ali um contacto com a audiência, directo $e$ espontaneo, que representa uma disponibilidade que já hoje não possuo.

A lição teve um eco inesperado na pacata e puritana Genebra e em muitos jornais diários, entre os quais o conhecido Journal de Genève que the dedicou coluna e meia na sua $2 .^{a}$ página, entusiástica, $e$, para mim, muito estimulante.

Hoje em Portugal eu suponho que pode ter ainda actualidade, ou melhor, cada vez mais actualidade, $e$ por isso eu acedi em publicá-lo na integra.

Pena è que não tenha apontamentos das intervenções dos participantes e mães de criancas com e sem problemas. $O$ diálogo foi vivo, durou até cerca das 2 horas da madrugada, o que é estranho num pais onde toda a gente se deita às 22 horas.

Tenho a impressão de que se o não tivesse interrompido, ainda agora lá estaria.

F. A., Junho de 1982

\footnotetext{
* Versão portuguesa de uma liçăo proferida na tecole des Parents em Génève no dia 20-3-1957.

** Psicanallsta, didacta da Socledade Portuguesa de Psicanállse.
}

A nossa conversa desta noite trata de um problema tão delicado e de tantas nuances que temo de vos decepcionar ao abordá-lo. Sei também que serei obrigado a deixar esquecidos uma quantidade de elementos respeitantes a interrogações angustiantes que todos os filhos põem aos seus pais neste dominio. Espero no entanto que me ponham depois as questões concretas de forma a que as minhas lacunas possam ser preenchidas.

Limitar-me-ei a algumas ideias gerais e a algumas regras bem estabelecidas, esperando que esta forma de abordar o assunto nos servirá de introdução para uma discussão viva e actual. Dividirei esta conversa em duas partes separadas, com vista a uma melhor compreensão do que terel para vos dizer. Como é do vosso conhecimento, os problemas de educação sexual põem-se a todos os pais na época da puberdade dos seus filhos. Com efeito, é nesta ocasião que o despertar das novas funções relativas ao mecanismo da reprodução da espécie colocam os pais e os filhos face a dificuldades particulares.

E nesta fase que a educação das funções reprodutivas põe problemas muito delicados dc moral sexual com caracteristicas particulares a cada civilização. ca,ção sexual propriamente dito e ele será objecto da segunda parte da minha exposição. A primeira parte que começarei a abordar imediatamente constitui o que chamarei de período preparatório à educação sexual.

Como é do vosso conhecimento, certamente, quando se diz sexual nem sempre se quer dizer genital, Esta úlitima palavra significa 
só a função sexual própria do adulto, isto é, a que já está completamente desenvolvida, todos os orgãos e sistemas correlacionados com esses orgãos assegurando a plena capacidade reprodutiva. Isto é importante, pois as outras funções do aparelho sexual existem já na criança pequena, e assim para melhor compreender os fenómenos da puberdade, é necessário conhecer tudo o que a precede cronologicamente. São estes precedentes e a forma como os pais os tratam que eu chamo o período de preparação da educação sexual. De facto, tudo isto constitul as bases, os pilares da verdadeira orientação sexual, que todos os pais conscientes da sua função deverão dar ao seu filho no momento da aproximação da puberdade. Assim a criança tem uma vida sexual muito antes de ter uma vida genital.

Muitos pais ignoram estes factos da vida sexual infantil, pois segundo uma lel natural, estes fenómenos sexuais da infância são destinados a serem esquecidos na sua maioria. Todos os desentendimentos entre pais e filhos neste sector são consequência deste esquecimento habitual. Também que a sexualidade infantil não tem o mesmo significado que a vida genital do adulto. Nas crianças os fenómenos sexuais são exclusivamente condicionados pelo prazer decorrente da excitação ocasional que é em seguida aprendida pelos órgãos sexuais. A motivação na procura deste prazer vem da organização particular ao espírito da criança, onde tudo está centrado sobre a sua enorme curiosidade e sobre a sua necessidade de tudo aprender. Sabemos todos que, antes mesmo de dominar a linguagem, a criança aprende a brincar com o seu orgão sexual, seja rapaz ou rapariga. Estes factos, que constituem a masturbação infantil, prolongam-se por vezes bastante tarde na adolescência, e não devem ser considerados anormals. Pelo contrário, significam a tentativa da criança de dominar o prazer da excitação sexual, e as experiências para a resolver.

Por vezes os pais têm dificuldade em suportar este estado de coisas, julgam o seu filho doente e tentam reprimir essas práticas. f um exro provocado pelo facto de o adulico ter a sua própria moral sexual e querer aplicá-la à criança. Ora, como já ò sublinhei, a moral sexual do adulto aplica-se a uma função já perfeitamente desenvolvida, o que não é o caso na criança.

A masturbação infantil é uma fase indispensável para atingir o completo desenvolvimento a que me refiro. Posso afirmar-vos, e comigo todos os médicos que estudaram este problema, que é a criança que não se masturba que mostra que algo de grave e de anormal se está a passar. Pouco a pouco a criança controla essa grande excitabilidade sexual e então reduz estas práticas às estritamente necessárias para o seu equilíbrio. No entanto, a falta de boas relações afectivas com os pais pode levá-la a procurar na masturbaç̃o uma compensação ao que lhe falta, ao mesmo título que as crianças que tiveram dificuldades alimentares e de desmame chupam no dedo.

Nestes casos a criança masturbar-se-á de uma forma excessiva, em frente de toda a gente e sem mostrar marcas de um certo pudor natural que as crianças aprendem muito cedo numa civilização em que as pessoas têm o costume de se vestir. Com o pudor do corpo vem o pudor da sexualidade. Se por volta dos $3 / 5$ anos a criança não desenvolve esta inibição natural das práticas masturbatórias, continuando a fazê-10 em frente dos adultos, então algo de anormal se está a passar, e o prolllema carece de cuidados médicos.

A fase que segue a das práticas solitárias é a das perguntas, a qual coincide com o desenvolvimento da linguagem.

Todos os pais conhecem estas perguntas, por vezes embaraçosas, que as crianças fazem na sua ansiedade de compreender o que thes escondem.

- De onde vêm os bébés? O que é que o pai faz na cama com a mãe? Porque é que os meninos são diferentes das meninas? E assim por diante até não mais ter fim.

Este período da infância é extremamente delicado, porque, ao contrário do que acontece com a masturbação, a criança tenta imitar os adultos e procura parceiros para estes prazeres sexuais. Evidentemente, va1 arranjar esses parceiros onde os encontra, quer dizer, no seu círculo imediato. Isto pode pôr problemas extremamente difíceis aos pais.

A criança não tem qualquer noção de relatividade, de reciprocidade, de papel social. Tudo nela é absoluto: se tem um desejo, esse desejo tem que ser satisfeito imedlatamente. A capacidade de esperar e de aguardar ocasióes favoráveis também não existe na criança. Assim, primeiro a criança é atraída pelo pal do sexo oposto. Este facto indiscutível provem da observação directa do comportamento infantil, apesar de ter sido primitivamente banido das recordações do adulto. 
Eis uma pequena história para ilustrar este facto:

Um dia uma menina de 5 anos, enquanto a sua mãe lhe dá banho, tem a seguinte conversa:

F-Mãe, posso casar com o pai quando for crescida?

$\mathrm{M}$ - Acho que é um bocado velho para ti.

$\mathrm{F}$ - (um pouco amuada) $E$ o $D r . X$, de quem gosto muito? (é o pediatra)

$\mathrm{M}-$ Esse também é casado, e penso que também é um bocado velho para ti.

$F-$ (completamente amuada e atirando com o sabão à parede) Entäo hei-de encontrar outro.

$\mathrm{M}$ - Tenho a certeza que sim, e muito melhor para ti.

Conto este episódio para mostrar o que implicitamente contém. A filha estava apalxonada pelo pai e queria casar com ele. Encontra uma dificuldade na satisfação do seu desejo e pensa imediatamente noutra pessoa, que no entanto é ainda bastante próxima, para substituir o pai. Finalmente, não encontrando nisso qualquer satisfação, renuncia com cólera, e reservando os seus sonhos para qualquer outro.

Trouxe-vos este exemplo porque o creio muito ilustrativo do que se passa. Notem também a atitude compreensiva da mãe, que compreende o que a filha the diz e a toma a sério.

Chamo a vossa atenção para o facto destes pequenos aborrecimentos que se passam no interior da criança, transferirem de uns para os outros, diriamos nós, até que se possam orientar para as personagens definitivas. Isto é importante e mostra a vantagem de não facilitar demasiado a fixação dos interesses da criança sobre os personagens dos pais, porque a criança pode ser seduzida inconscientemente por um dos pais e ficar para sempre presa a ele, o que mais tarde pode ser causa de dificuldades sexuais na escolha do parceiro conveniente. Esta sedução pode também dar mais tarde a idealização de um parceiro sexual perfeito, o que evidentemente não existe senão na imaginação e, não o encontranđo na realidade, traz para o indivíduo as consequências implícitas da insatisfação de jamais encontrar o que procura.

Assim é importante que os pais estejam conscientes destes perigos, porque, fazendo conhecer à criança outros casais amigos, removem a atracção pelos pais que é perigosa para 0 desenvolvimento da sexualidade infantil.
Neste período, a criança interessa-se também por outras crianças, do mesmo ou de outro sexo. f a fase dos jogos sexuals entre crianças, e até enitre irmãos. Isto choca horrivelmente 0 adulto, pois evidentemente não existem vestígios de uma moral sexual, levando os pais a obstinarem-se em exercer uma repressão.

O conselho que posso dar neste capítulo é de o adulto que se apercebe destes jogos fingir que não viu nada. $\mathrm{E}$ o que se pode fazer de melhor pela criança. Não há seguramente nenhum pai que não fique angustiado ao saber das práticas do seu filho, sobretudo se elas tomarem (o que é de regra) um aspecto que para o adulto é do domínio da perversidade.

Aqui também se passa um facto semelhante ao que acontece com a masturbação: todas as crianças têm tendências perversas, no entanto, só se tornarão perversas se tiverem carências afectivas por parte dos pais.

f um facto que as perversões infantis são muito mais frequentes em crianças educadas fora de um quadro familiar consistente. A criança pode procurar na perversão uma compensação daquilo que the falta. Se a criança tiver actividades perversas sem mostrar vergonha ou inibição, é caso para pensar que existe uma perturbação e será preciso fazê-la tratar. Se isto for correctamente feito, não há perigo que estes fenómenos se tornem em comportamento perverso mais tarde, no adulto.

Finalmente, após um período dito de latência, em que a criança, já na escola, parece desinteressar-se da sexualidade e procura dominar de uma forma mais intelectualizada as suas forças (pulsões?) sexuais, entramos na puberdade.

Sabem que a puberdade é caracterizada pela aparição da última função sexual, a ejaculação nos rapazes e a menstruação nas raparigas, e é varlável cronologicamente em relação ao clima, à constituição da criança, à sua raça, etc..

Devem também saber que os nórdicos têm uma puberdade mais tardia que os meridionais, que os loiros são também monos precoces que os morenos, etc.

O que é importante é apercebermo-nos dos fenómenos que precedem a aproximação da puberdade. Penso que toda a gente os conhece pelo menos nos seus aspectas físicos: desenvolvimento do sistema piloso, borbulhas na pele, mudança da voz, etc..

Começa então a verdadeira educação sexual. Dar-vos-ei os princípios de orientação 
desta educação, voltando a cada um para discutir as razões e porque é que se estabelecem. (O que os orienta, motiva).

$10^{\circ}$ - A educação sexual deve ser orientada pelo pai do mesmo sexo.

$2 .^{\circ}$ - A base de toda a educação sexual deve ser centrada sobre o respeito pelo outro sexo e a aceitação integral do sexo oposto. Esta questão é certamente a mais importante do assunto que estamos a tratar: a aceitação de todas as funções de carácter viril ou feminino, fora de toda a noção de valor, ou seja, a possibilidade de assumir o papel que nos é destinado pela natureza sem invejar aquele que a mesma natureza destinou aos outros.

Isto é muito difícil de conseguir, pode-se mesmo perguntar se não é um ponto de vista. Seria preciso para que losse possível chegar a esta perfeição, ter chegado a uma maturação completa, a qual se traduziria por uma sexualidade completamente normal. Ora a normalidade neste domínio, como noutros, è uma definição que se pode dar (tal como a que vos proponho), mas que na realidade é igualmente inexistente.

Tal como não há um estado de saúde integral, não existe uma normalidade sexual absoluta. Pode-se estar relativamente contente com a sua sexualidade: isto quer dizer que esta funciona na medida dos desejos de cada um, mas mais nada.

Estas considerações um pouco espectaculares visam a dar-vos uma noção real do problema, que espero poderá ajudar-vos a abster-vas do perfeccionismo, que no quadro do erotismo será sobretudo uma forma de angústia. No entanto será útil conservar a noção de perfeição, ao mesmo título que se pode manter um ideal como ideia de orientação para a existência, sabendo-se que nunca será atingido, pois quando isso acontecesse deixaria de existir, para termos que procurar outro.

No que toca à aceitação do papel sexual, compatível com o que a natureza atribui, é preciso saber que a característica da sexualidade viril é a actividade que empreende, e que o carácter fundamental da feminilidade é a passividade receptiva. Isto tanto no plano psicológico como na função física. As mulheres invejam aos homens esta actividade, que se traduz numa maior libertação sexual do «mal». Os homens invejam às mulheres a possibilidade obtida, na sua receptividade, de ter filhos. Estas invejas cruzadas são o que é ha- bitual chamar, a luta dos sexos. Objectivamente, isto é ridículo, pois os sexos sendo diferentes nas suas funções não podem ser comparáveis num plano de valores: a função sexual de um sexo assegura a do sexo oposto, precisamente por serem complementares.

$3 .^{\circ}$ - A moral sexual ensinada à criança deve ser a do meio social, nivel cultural e civilização a que os pais pertencem. Isto porque todas as crianças tomam os pais como modelos, e na adolescência têm ainda muita necessidade de os considerar como ideais. Mais tarde 0 adolescente escolherá outros modelos entre os que a civilização the oferece.

Se se ensinar à crīança outros conceitos do que os que podem ser seguidos pelos pais isto irá desorientá-la, e talvez tornar-se numa origem de ansiedade e desconfiança. A frase: «Estes são os nossos princípios, os que nos trouxeram satisfação, aconselho-te a segui-los até ao momento em que possas escolher outros mais pessoais e adequados às tuas necessidades», poderá resumir a minha ideia do que considero a atitude correcta por parte dos pais.

$4 .^{\circ}-$ Nenhum pai, por muito preparado que esteja, pode fornecer ao seu filho uma educação sexual válida se ele próprio tiver problemas ou ansiedades no que respeita à sua própria sexualidade. $\hat{E}$ este último ponto que me permitirei comentar e é também o mais delicado.

Já sabem que não há normalidade sexual absoluta. Neste campo as perturbações são tanto mais frequentes quanto não se fala nelas. t vergonhoso falar de sexualidade na nossa civilização. As pessoas que têm coragem de enfrentar dificuldades sexuais e de consultar por causa delas, são raríssimas. Isto tem por consequência que o pai terá tendência a deixar na sombra precisamente o que mais 0 preocupa. A criança percebê-lo-á de qualquer modo e ficará ainda mais preocupada que 0 pai. Há aqui um fenómeno muito corrente de potencialização, em que o que é uma ligeira dificuldade no pai pode tornar-se em grave perturbação na criança. A recomendação que posso dar aos pais neste campo é que devem proceder a um exame de consciência honesto antes de enveredar pela educação sexual dos filhos. Se existe uma dificuldade ou um receio de qualquer espécie; então mais vale dirigir a criança a outra pessoa. O pedtatra, o médico da familia (que infelizmente está a desa- 
parecer), o pessoal dos centros psico-educativos, estão particularmente indicados para esse fim.

Por vezes um amigo intimo pode mais facilmente encarregar-se da educação sexual dos nossos filhos do que nós mesmos. Podemos retribuir-lhe fazendo o mesmo com os seus filhos, pois é muito mais fácil ser livre e objectivo com crianças que não tenham connosco a. ligação profunda que todos os pais têm com 0 seu próprio filho.

Hoje em dia há também a tendência de fazer orientar a educação sexual por professores na escola. Penso que isso é bom, pois a educação no interior de um grupo de elementos semelhantes é sempre mals fecunda do que uma educação centrada num único indivíduo.

Não me quero alongar mais, para dar lugar às vossas perguntas.

Antes de acabar queria apenas deixar-vos um facto biológico preciso, para que sobre ele possam reflectir calmamente.

Pensem que só o trabalho feito pelo coração do homem em 24 horas é mais ou menos equivalente à força necessária para levantar 100.000 quilos à altura de um metro. Se tiverem este cálculo em conta, poderão como eu, fazer uma vaga Idela das forças chamadas a realizar este esforço, e muitas outras colsas. Podem em seguida reflectir sobre as forças que se podem assimilar à energia investida no aparelho reprodutivo, ou seja, às forças da sexualidade, e finalmente se não tiverem tendências vertiginosas, compreender a importância de tudo o que desajeitadamente tentei fazer-lhes compreender.

\section{SUMMARY}

In this communication some years ago in Geneva's Ecole des Parents, the author considers sexual education in children and adolescents.

Sexual education in childhood refers to the attitudes that parents should take when facing auto-erotic activities (masturbation) in the child, as well as curiosity and infantile sexual theories and early phenomena of oedipal attraction.

The principles and rules (now much more verbal than before) convenient to govern the sexual education of adolescents are, according to the author, the following:

1) Sexual education should be oriented by the parent of the same sex.

2) Integral respect of the opposite sex.

3) It is advantageous for parents to be aware of anxieties they have concerning certain areas of sexuality. If such is the case, sexual education should be left to a third party (friend of the family, family doctor, teacher in school). 